\title{
Linear Well-Defined Polyamines via Anionic Ring-Opening Polymerization of Activated Aziridines: From Mild Desulfonylation to Cell Transfection
}

\author{
Tassilo Gleede, ${ }^{\dagger}$ Fangzhou Yu, ${ }^{\ddagger}$ Ying-Li Luo, ${ }^{\ddagger}$ Youyong Yuan, ${ }^{\ddagger}$ Jun Wang, ${ }^{\ddagger}$ and Frederik R. Wurm* ${ }^{*} \dagger \odot$ \\ ${ }^{\dagger}$ Max-Planck-Institut für Polymerforschung (MPI-P), Ackermannweg 10, D-55128 Mainz, Germany \\ ${ }^{\ddagger}$ National Engineering Research Center for Tissue Restoration and Reconstruction, School of Biomedical Sciences and Engineering, \\ South China University of Technology, Guangzhou, China
}

\section{Supporting Information}

ABSTRACT: Linear polyethylenimine (L-PEI), a standard for nonviral gene delivery, is usually prepared by hydrolysis from poly(2-oxazoline)s. Lately, anionic polymerization of sulfonamide-activated aziridines had been reported as an alternative pathway toward well-defined L-PEI and linear polyamines. However, desulfonylation of the poly(sulfonyl aziridine)s typically relied on harsh conditions (acid, microwave) or used a toxic solvent (e.g., hexamethylphosphoramide). In addition, the drastic change of polarity requires solvents, which keep poly(sulfonyl aziridine)s as well as L-PEI in solution, and only a limited number
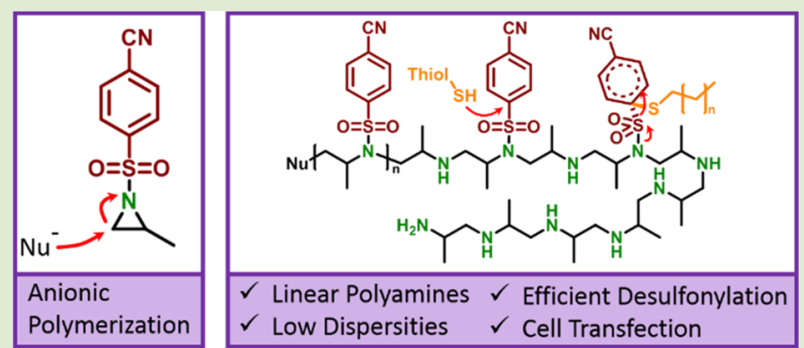
of strategies were reported. Herein, we prepared 1-(4-cyanobenzenesulfonyl) 2-methyl-aziridine (1) as a monomer for the anionic ring-opening polymerization. It was polymerized to well-defined and linear poly(sulfonyl aziridine)s. The 4cyanobenzenesulfonyl-activating groups were removed under mild conditions to linear polypropylenimine (L-PPI). Using dodecanethiol and diazabicyclo-undecene (DBU) allowed $\geq 98 \%$ desulfonylation and a reliable purification toward polyamines with high purity and avoiding main-chain scission. This method represents a fast approach in comparison to previous methods used for postpolymerization desulfonylation and produces linear well-defined polyamines. The high control over molecular weight and dispersities achieved by living anionic polymerization are the key advantages of our strategy, especially if used for biomedical applications, in which molecular weight might correlate with toxicity. The synthesized polypropylenimine was further tested as a cell-transfection agent and proved, with $16.1 \%$ transfection efficiency of the cationic nanoparticles, to be an alternative to L-PEI obtained from the 2-oxazoline route. This general strategy will allow the preparation of complex macromolecular architectures containing polyamine segments, which were not accessible before.
$\mathrm{L}$ inear polyamines, especially polyethylen- or propylenimine, would be ideal building blocks for macromolecular architectures for $\mathrm{pH}$-responsive or metal-chelating (nano)materials. However, to date, only a very limited number of polymers with well-defined polyamine segments have been reported. ${ }^{1}$ Living anionic polymerization (LAP) is the superior method when it comes to the synthesis of well-defined polymers with low dispersity and complex architectures. In direct analogy to the oxy-anionic ring-opening polymerization of epoxides, LAP of sulfonyl-activated aziridines gives access to well-defined linear poly(sulfonyl aziridine)s, where $\mathrm{N}$-substituted nitrogen is part of the polymer backbone. ${ }^{2}$ However, the free polyamines are only obtained, after removal of the sulfonamides under typically harsh conditions, which potentially resulted in the scission of the main chain and incomplete desulfonylation or by using toxic solvents, such as hexamethylphosphoramide (HMPA). ${ }^{3}$

LAP of sulfonyl aziridines stands out from oxy- and carbanionic polymerization by its unique tolerance against water and other protic additives due to the low nucleophilicity of the growing chain end. ${ }^{4}$ Polymerization of sulfonyl aziridines was also achieved by organo-catalyzed polymerization with a variety of superbases ${ }^{5}$ and carbenes, recently. ${ }^{6-8}$ The electron-withdrawing effect of the activating $\mathrm{N}$-substituent directly correlates to the propagation rate coefficient and allowed the design of sequence-controlled gradient copolymers by competitive copolymerization of different aziridines in a one-pot synthesis. ${ }^{9,10}$ Sulfonyl aziridines copolymerized with ethylene oxide gave access to amphiphilic block copolymers by a fast one-pot polymerization procedure, due to highly different propagation rates. ${ }^{11}$ Those amphiphilic block copolymers were used as emulsifiers and for the preparation of multiblock copolymers. A similar protocol for a one-step synthesis was more recently established by Rupar and coworkers, to access block copolymers from sulfonyl-activated azetidines and aziridines. ${ }^{12}$ Block polyamines with defined $\mathrm{N}-$ $\mathrm{N}$ distances of 2 or $3 \mathrm{CH}_{2}$ groups were prepared. Other block

Received: October 11, 2019

Accepted: December 3, 2019

Published: December 11, 2019 
copolymers of aziridines with styrene $e^{13}$ or lactide ${ }^{6}$ were also prepared recently, relying on sequential monomer addition.

Even though poly(sulfonyl aziridine)s could be beneficial materials for several applications, in which hydrophobicity or high thermal resistance might be beneficial, to date they are mainly considered as intermediates to polyamines after removal of the sulfonyl groups. Linear polyethylenimines (LPEIs) of well-defined size and dispersity are important for nonviral gene transfection. ${ }^{14}$ L-PEI is also used in applications such as antifouling coatings, ${ }^{15}$ chelation, ${ }^{16}$ or for $\mathrm{CO}_{2}$ capture. ${ }^{17,18}$ However, only a limited number of synthetic strategies give access to L-PEI: the cationic ROP (CROP) of aziridines only provides branched polymers, and probably the most common pathway toward L-PEI is the acidic or basic hydrolysis of poly(2-oxazoline)s. ${ }^{19-22}$ The synthesis of poly(2oxazoline)s was developed more than 50 years ago and was continuously improved. $^{23,24}$ Today, CROP of 2-oxazolines can be conducted as living cationic polymerization, providing welldefined polymers with low dispersities. ${ }^{25-27}$ Other methods are rare, and one to be mentioned is the mild acidic hydrolysis of poly( $N$-pyranyl ethylenimine $) s .{ }^{28}$ However, as the CROP suffered from chain transfer and termination reactions, this strategy was not further continued.

Herein, we developed a strategy based on living anionic ROP to linear polyamines. LAP avoids termination reactions and gives access to complex polymer architectures. Several monomer classes are polymerized by LAP, and aziridines might be a powerful addition to the monomer set for additional complex structures. Sulfonyl aziridines gave access to polyamines by different desulfonylation strategies. ${ }^{3,29,30}$ However, the need for toxic solvents or harsh reaction conditions (e.g., highly acidic, microwave, ${ }^{29}$ or lithium metal in $\mathrm{HMPA}^{30}$ ) made this strategy less attractive compared to the oxazoline route. Additionally, chain scission had been reported, and the workup procedures reduced yields in some cases.

Sulfonamides, however, have adjustable stability depending on their substitution pattern, which can be utilized to tailor desulfonylation conditions. ${ }^{31}$ While tosyl groups need strong acids or reducing conditions to be removed from the polymer, desulfonylation of nitrophenylsulfonyl groups had been removed under much milder conditions, recently. ${ }^{32}$ However, the purity and yield of the obtained L-PEI were lower compared to L-PEI from poly(2-oxazoline)s. Further, the nitrophenylsulfonyl-activated monomer proved to be highly reactive, and spontaneous polymerization was reported. ${ }^{32}$

Here, we present the synthesis and polymerization of the activated sulfonyl aziridine (1) (Scheme 1). The monomer 1 was prepared by the reaction of 2-methyl-aziridine with 4cyanobenzenesulfonyl chloride and purified crystallization from tert-butyl methyl ether. The monomer was obtained as

Scheme 1. Anionic Ring-Opening Polymerization of 1-(4Cyanobenzenesulfonyl) 2-Methyl Aziridine (1)

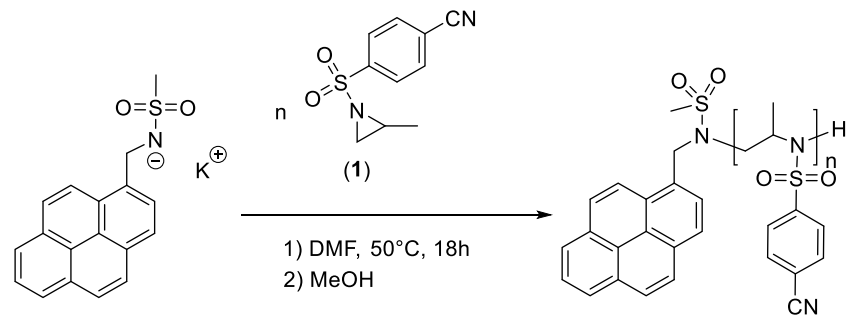

a white powder with a $93 \%$ yield and was bench-stable over several weeks without polymerization.

The ${ }^{1} \mathrm{H}$ NMR spectrum of 1 revealed the typical resonance pattern for a 2-substituted sulfonyl aziridine with resonances from $3.53 \mathrm{ppm}(\mathrm{m}), 2.24 \mathrm{ppm}$ (d), and $1.34 \mathrm{ppm}$ (d) (Figure $\mathrm{S} 1)$. In the ${ }^{13} \mathrm{C}$ NMR spectrum, the resonances of the ring carbons were detected at 36.8 and $35.6 \mathrm{ppm}$, respectively, indicating a stronger electron-withdrawing effect of the cyanobenzenesulfonyl group compared to other sulfonyl aziridines (Figure S2, note: the tosyl-substituted analogue exhibited ${ }^{13} \mathrm{C}$ NMR resonances at higher field (ca. 35.9, 34.7 ppm)). ${ }^{33}$ ESI mass spectrometry proved the successful preparation of 1 with a single mass peak for the protonated monomer at $223.1 \mathrm{Da}\left(\mathrm{MH}^{+}\right.$, Figure S3). For the polymerization of 1 , the monomer was freshly recrystallized and dissolved in DMF at $50{ }^{\circ} \mathrm{C}$, and the initiator solution was added. The polymers were purified by precipitation from the crude reaction mixture into cold methanol or diethyl ether with yields of $68-96 \%$. Polymers with degrees of polymerization (DP) from 25 to 200 repeating units, $M_{n}=6300-$ $44700 \mathrm{~g} \mathrm{~mol}^{-1}$ were synthesized with narrow to moderate molecular weight distributions $(\nexists=1.15-1.43$, Figure 1 and

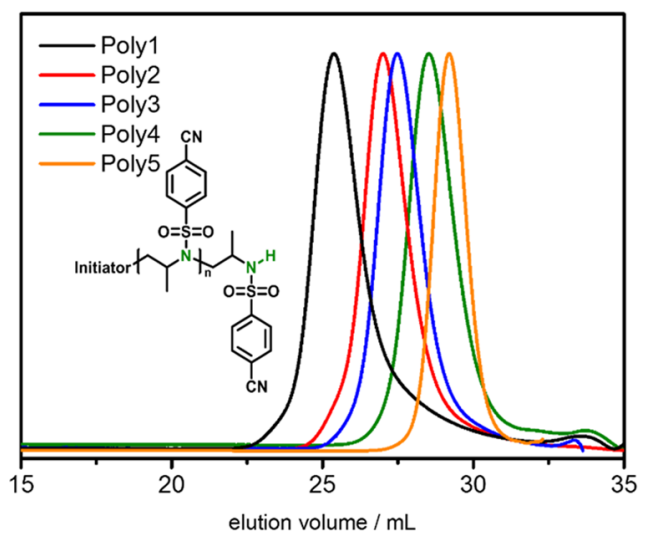

Figure 1. SEC elugrams of Poly1-Poly5 (in DMF, RI detection).

Table 1). The increased molar mass dispersities with an increasing degree of polymerization might be caused by decreased solubility of the polymers as we had encountered for previous poly(sulfonyl aziridine)s. ${ }^{1} \mathrm{H}$ NMR spectroscopy proved the successful formation of the polymer, with typical resonances for poly(sulfonyl aziridine)s (cf. Figure 2 and labels in the spectra).

Table 1. Molar Mass Characterization of Different Polymers Based on Monomer 1

$\begin{array}{ccccc}\# & \text { DP } & M_{\mathrm{n}} / \mathrm{g} \mathrm{mol}^{-1} & M_{\mathrm{n}} / \mathrm{g} \mathrm{mol}^{-1} & Ð \\ \text { Poly1 } & 200^{d} & 44700^{d} & 8600^{b} & 1.43^{b} \\ \text { Poly2 } & 90^{a} & 20500^{a} & 6500^{b} & 1.14^{b} \\ \text { Poly3 } & 79^{a} & 17500^{a} & 5200^{b} & 1.18^{b} \\ \text { Poly4 } & 42^{a} & 9300^{a} & 3500^{b} & 1.15^{b} \\ \text { Poly5 } & 30^{d} & 6300^{d} & 1900^{b} & 1.12^{b} \\ \text { PPI-1 } & 215^{a} & 12400^{a} & 17800^{c} & 1.22^{c} \\ \text { PPI-2 } & 83^{a} & 5000^{a} & 12100^{c} & 1.29^{c} \\ \text { PPI-5 } & 30^{d} & 1800^{d} & 5.600^{c} & 1.16^{c}\end{array}$

${ }^{a}$ Determined via ${ }^{1} \mathrm{H}$ NMR. ${ }^{b}$ Determined via SEC (DMF vs PEO standards). ${ }^{c}$ Determined via SEC in hexafluoroisopropanol (HFIP). $d_{\text {Theoretical value. }}$ 


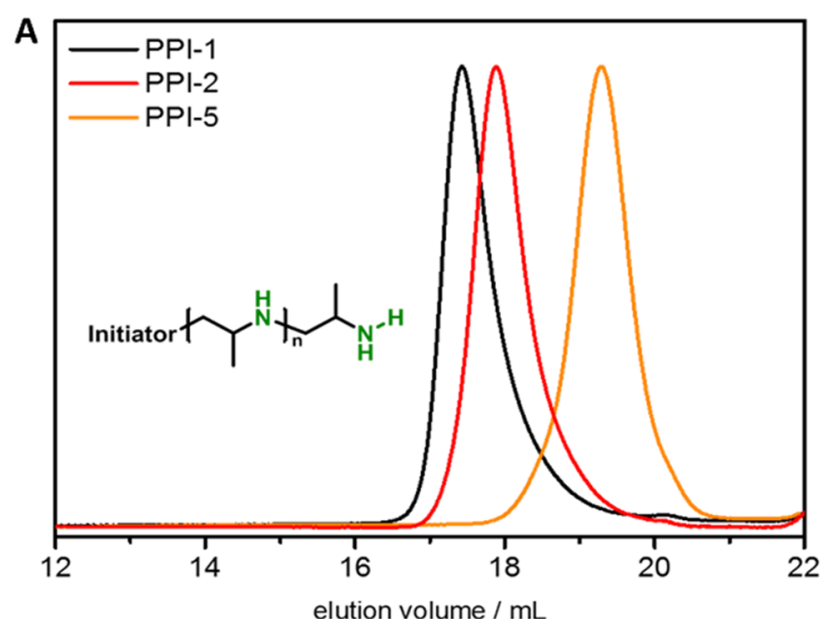

B

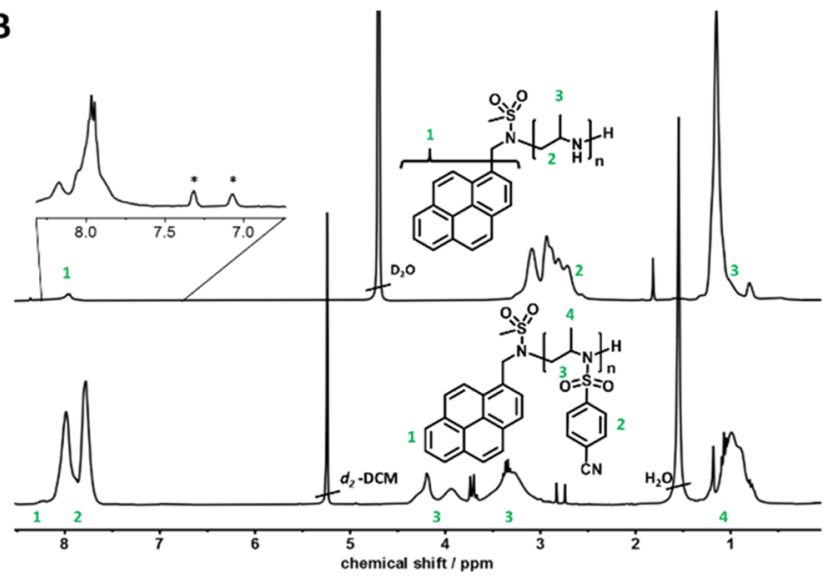

Figure 2. Desulfonylation of Poly2: (A) SEC traces of polypropylenimines PPI-1 (black), PPI-2 (red), and PPI-5 (orange) in HFIP. (B) Overlay of the ${ }^{1} \mathrm{H}$ NMR spectra of Poly2 $\left(\right.$ in $\mathrm{CD}_{2} \mathrm{Cl}_{2}$ ) and PPI-2 (in $\mathrm{D}_{2} \mathrm{O}$ ). *Residues of aromatic signals.

The polyamines were released by a mild desulfonylation via a nucleophilic attack to the electron-deficient 4-cyanophenylsulfonyl group by a thiolate forming a Meisenheimer complex (Scheme 2). Desulfonylation was performed in DMF with a 5fold excess of 1-dodecanethiol and DBU as a base (note: the cyanobenzenesulfonyl groups can be removed directly after the polymerization by adding DBU and the thiol or after workup of the intermediate poly(sulfonyl aziridine)).

Linear polypropylenimine (L-PPI) was isolated after the addition of ethyl acetate to the crude mixture and extraction with water. L-PPI was obtained after subsequent dialysis and lyophilization with ca. $40 \%$ yield. As the desulfonylation occurred under very mild conditions, also the SEC traces of the linear PPIs exhibited narrow molar mass dispersities, comparable to the starting materials. In addition, the fluorescent initiator remained intact (Scheme 2A), proving the possibility to install further functionalities at the $\alpha$-position of the polymer chain end. The PPIs (1, 2, and 5) are eluted at earlier elution volumes compared to the precursors Poly1, Poly2, and Poly3 (compare SEC in HFIP, Figures S4 and S5), which is probably related to a larger hydrodynamic radius than the precursor polymer in HFIP. The desulfonylation was reproducible also for high molar mass PPIs (Table 1, PPI-1), indicating that during the process chain scission was avoided.

The purified L-PPI was analyzed by ${ }^{1} \mathrm{H}$ NMR (Figures 2 and S6) and ${ }^{13} \mathrm{C}$ NMR spectroscopy (Figure S7) proving that a
Scheme 2. (A) Desulfonylation of Poly1 to Linear PPI (the Photo Shows the Fluorescence of the PPI in Water $(2 \mathrm{mg} /$ $\mathrm{mL}, 266 \mathrm{~nm}$ )) and (B) Mechanism of Desulfonylation by Nucleophilic Addition of the Thiolate via a Meisenheimer Intermediate, Followed by the Release of Sulfur Dioxide, Thioether, and the Polyamine

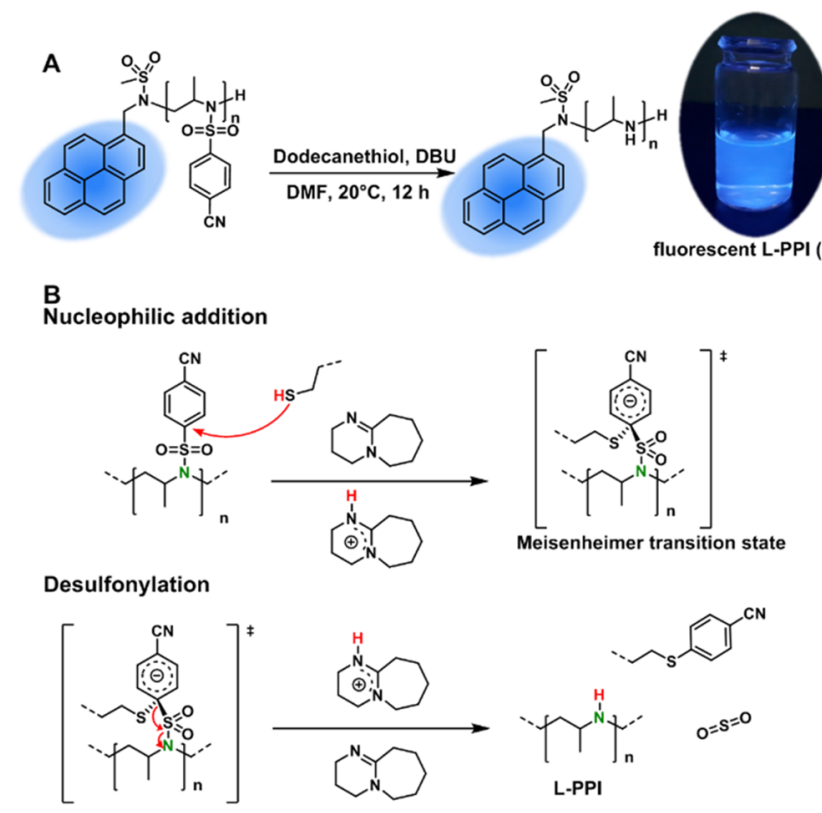

high to quantitative desulfonylation of at least $98 \%$ was achieved. Similar values are reported for the hydrolysis of commercially available L-PEI from poly(2-oxazoline)s with 92-93\% hydrolysis. ${ }^{27}$ Laboratory-produced L-PEI from poly(2-oxazoline)s with $99 \%$ to quantitative hydrolysis efficiency for L-PEI was reported, ${ }^{27}$ similar to the herein reported L-PPI from poly(sulfonyl aziridine)s. MALDI ToF MS of PPI-2 (Figure S8) underlines the effective desulfonylation. All the main signals in the spectrum were attributed to PPI, confirming the removal of the cyanobenzenesulfonyl groups and showing only the repeating unit of propyleneimine (with $57.1 \mathrm{~g} \mathrm{~mol}^{-1}$ ). Other peaks for molar masses referring to the partly deprotected polymer were not detected. Compared to the results of SEC and ${ }^{1} \mathrm{H}$ NMR, the MALDI ToF MS analysis underestimated the mass of the polymer, and only smaller fractions of polyamine were detected, which is probably due to mass discrimination effects. It was reported that the multiple charges on polyamines resulted in complexation to impurities during the sample preparation and adhesion to the metal substrate, thus reducing the resolution of mass spectra. ${ }^{34}$

The linear PPI-5 was used to study cellular transfection efficiency. The gene-loaded cationic PPI-5 nanoparticles (abbreviated as PPI5-DNA-NPs below) were obtained by means of electrostatic attraction between the anionic plasmid DNA and the cationic PPI. Figure S9 shows the representative size distribution profiles and zeta potentials of the nanoparticles. The particle size and polydispersity index of PPI5DNA-NPs $(\mathrm{N} / \mathrm{P}=40)$ were $89 \mathrm{~nm}$ and 0.206 , respectively, demonstrating a relatively narrow particle size distribution. In addition, as $\mathrm{N} / \mathrm{P}$ increased, the surface charges with zeta potentials changed from -20.8 to $24.5 \mathrm{mV}$ were measured. The results of agarose gel electrophoresis (Figure S10) proved that PPI5-DNA-NPs bind with DNA to various degrees with different $\mathrm{N} / \mathrm{P}$ ratio in the complex. There was decreasing free 


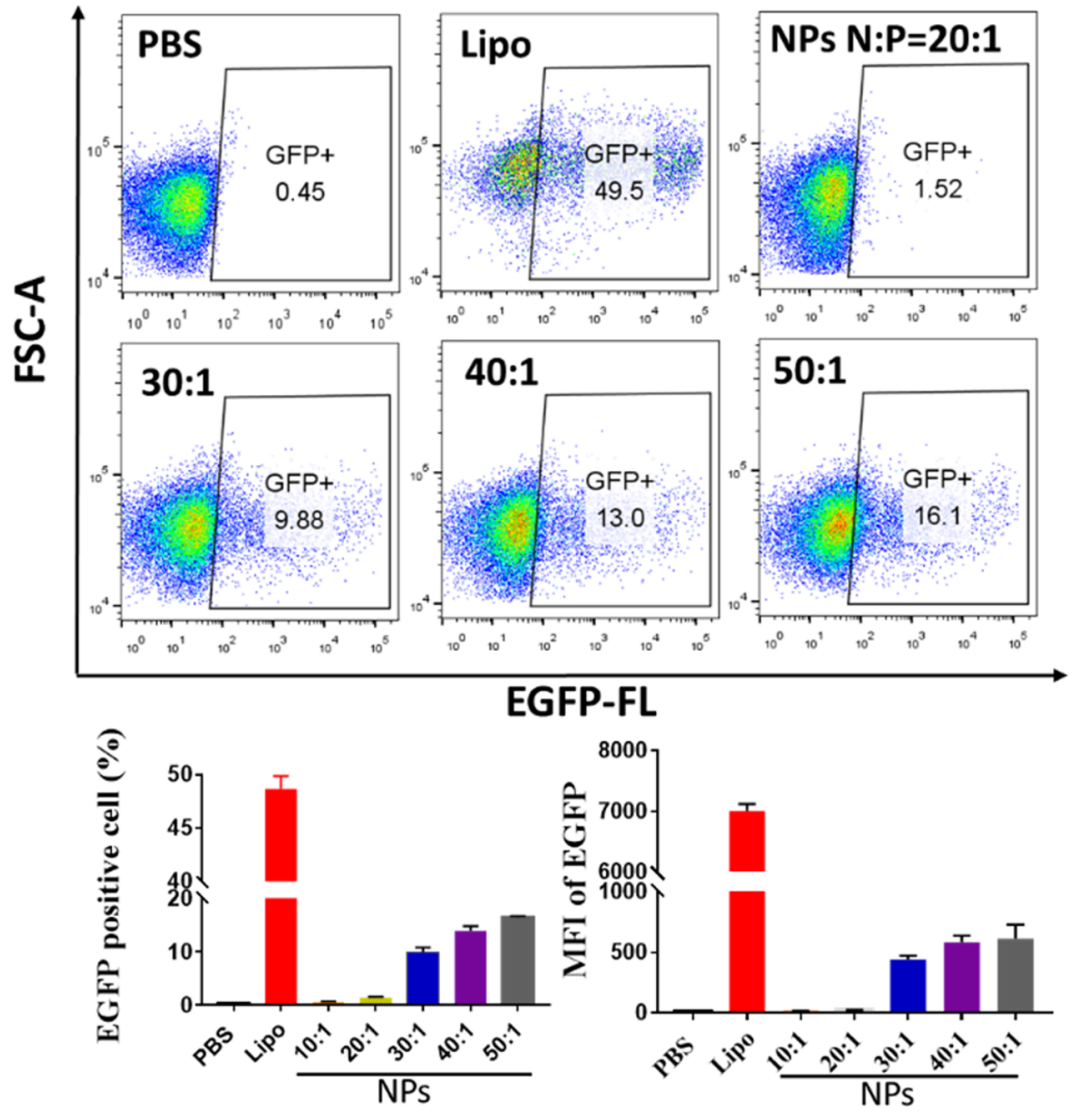

Figure 3. GFP expression levels after transfection using lipofectamine and PPI5-DNA-NPs (N:P = 20:1, 30:1, 40:1, 50:1).

DNA present in the lane with the increase of the ratio of PPI5/ DNA. When the N/P of NPs reached 20:1 or above, almost all DNA was combined with NPs without free DNA bands in the visible lane. Detection of the expression of EGFP was carried out using an inverted fluorescent microscope (Figure S12) and flow cytometry (Figure 3 ). The results underlined that PPI5DNA-NPs successfully transferred plasmid DNA into 293T cells, and the transfection efficiency can reach $16.1 \%$ when the N/P of PPI5-DNA-NPs is 50:1 (Figure 3). To the best of our knowledge, this is the first example for a gene transfection conducted with a polyamine, prepared from poly(sulfonyl aziridine)s.

In summary, we presented a novel activated sulfonyl aziridine, 1, a monomer for the anionic ring-opening polymerization. Similar to other monomers of the family of sulfonyl aziridines, well-defined linear poly(sulfonyl aziridine)s were obtained by ROP. In contrast to previously reported highly activated aziridines, 1 was bench stable and did not undergo spontaneous polymerization. More importantly, mild desulfonylation via a nucleophilic aromatic substitution removed the 4-cyanobenzenesulfonyl groups almost quantitatively, and linear polypropylenimines were obtained. We believe this strategy is to date the fastest and mildest pathway to well-defined linear polyamines. The reaction conditions avoid very low or high temperatures, harsh reaction conditions, and toxic solvents (such as HMPA) and exhibit an easy workup procedure, to access linear polyamines by anionic ringopening polymerization, which further allows the combination with other anionic polymerization techniques for macromolecular architectures. We further demonstrated the successful application of PPI as a cell transfection agent; the cationic L-PPI can bind DNA through electrostatic attraction, and the gene vectors PPI5-DNA-NPs were used successfully to transfer the reporter gene EGFP to $293 \mathrm{~T}$ cells, leading to gene expression and subsequent protein synthesis. We believe this general strategy will broaden the synthetic toolbox for the preparation of complex macromolecular architectures containing well-defined polyamine segments.

\section{ASSOCIATED CONTENT}

\section{Supporting Information}

The Supporting Information is available free of charge at https://pubs.acs.org/doi/10.1021/acsmacrolett.9b00792.

Experimental and additional characterization data (PDF)

\section{AUTHOR INFORMATION}

\section{Corresponding Author}

*E-mail: wurm@mpip-mainz.mpg.de.

ORCID $\odot$

Youyong Yuan: 0000-0003-2784-3780

Frederik R. Wurm: 0000-0002-6955-8489

\section{Author Contributions}

The manuscript was written through the contributions of all authors. All authors have given approval to the final version of the manuscript.

\section{Notes}

The authors declare no competing financial interest. 


\section{ACKNOWLEDGMENTS}

T.G. and F.R.W. thank the Deutsche Forschungsgemeinschaft (DFG WU 750/7-1) for funding. The authors thank Prof. Dr. Katharina Landfester for continuous support. The authors thank Markus Lamla (Uni. Ulm, Germany) for MALDI ToF measurement.

\section{REFERENCES}

(1) Gleede, T.; Reisman, L.; Rieger, E.; Mbarushimana, P. C.; Rupar, P. A.; Wurm, F. R. Aziridines and azetidines: building blocks for polyamines by anionic and cationic ring-opening polymerization. Polym. Chem. 2019, 10 (24), 3257-3283.

(2) Stewart, I. C.; Lee, C. C.; Bergman, R. G.; Toste, F. D. Living Ring-Opening Polymerization of N-Sulfonylaziridines: Synthesis of High Molecular Weight Linear Polyamines. J. Am. Chem. Soc. 2005, 127 (50), 17616-17617.

(3) Rieger, E.; Gleede, T.; Manhart, A.; Lamla, M.; Wurm, F. R. Microwave-Assisted Desulfonylation of Polysulfonamides toward Polypropylenimine. ACS Macro Lett. 2018, 7, 598-603.

(4) Gleede, T.; Rieger, E.; Liu, L.; Bakkali-Hassani, C.; Wagner, M.; Carlotti, S.; Taton, D.; Andrienko, D.; Wurm, F. R. Alcohol- and Water-Tolerant Living Anionic Polymerization of Aziridines. Macromolecules 2018, 51 (15), 5713-5719.

(5) Wang, X.; Liu, Y.; Li, Z.; Wang, H.; Gebru, H.; Chen, S.; Zhu, H.; Wei, F.; Guo, K. Organocatalyzed Anionic Ring-Opening Polymerizations of N-Sulfonyl Aziridines with Organic Superbases. ACS Macro Lett. 2017, 6, 1331-1336.

(6) Bakkali-Hassani, C.; Coutouly, C.; Gleede, T.; Vignolle, J.; Wurm, F. R.; Carlotti, S.; Taton, D. Selective Initiation from Unprotected Aminoalcohols for the N-Heterocyclic Carbene-Organocatalyzed Ring-Opening Polymerization of 2-Methyl-N-tosyl Aziridine: Telechelic and Block Copolymer Synthesis. Macromolecules 2018, 51 (7), 2533-2541.

(7) Bakkali-Hassani, C.; Rieger, E.; Vignolle, J.; Wurm, F. R.; Carlotti, S.; Taton, D. The organocatalytic ring-opening polymerization of N-tosyl aziridines by an N-heterocyclic carbene. Chem. Commun. 2016, 52 (62), 9719-22.

(8) Bakkali-Hassani, C.; Rieger, E.; Vignolle, J.; Wurm, F. R.; Carlotti, S.; Taton, D. Expanding the scope of $\mathrm{N}$-heterocyclic carbene-organocatalyzed ring-opening polymerization of $\mathrm{N}$-tosyl aziridines using functional and non-activated amine initiators. Eur. Polym. J. 2017, 95, 746-755.

(9) Rieger, E.; Alkan, A.; Manhart, A.; Wagner, M.; Wurm, F. R. Sequence-Controlled Polymers via Simultaneous Living Anionic Copolymerization of Competing Monomers. Macromol. Rapid Commun. 2016, 37 (10), 833-9.

(10) Rieger, E.; Blankenburg, J.; Grune, E.; Wagner, M.; Landfester, K.; Wurm, F. R. Controlling the Polymer Microstructure in Anionic Polymerization by Compartmentalization. Angew. Chem., Int. Ed. 2018, 57 (9), 2483-2487.

(11) Gleede, T.; Rieger, E.; Blankenburg, J.; Klein, K.; Wurm, F. R. Fast Access to Amphiphilic Multiblock Architectures by the Anionic Copolymerization of Aziridines and Ethylene Oxide. J. Am. Chem. Soc. 2018, 140 (41), 13407-13412.

(12) Reisman, L.; Rowe, E. A.; Jackson, E. M.; Thomas, C.; Simone, T.; Rupar, P. A. Anionic Ring-Opening Polymerization of N(tolylsulfonyl)azetidines To Produce Linear Poly(trimethylenimine) and Closed-System Block Copolymers. J. Am. Chem. Soc. 2018, 140 (46), 15626-15630.

(13) Thomi, L.; Wurm, F. R. Aziridine Termination of Living Anionic Polymerization. Macromol. Rapid Commun. 2014, 35 (5), 585-9.

(14) Jager, M.; Schubert, S.; Ochrimenko, S.; Fischer, D.; Schubert, U. S. Branched and linear poly(ethylene imine)-based conjugates: synthetic modification, characterization, and application. Chem. Soc. Rev. 2012, 41 (13), 4755-67.
(15) Francolini, I.; Vuotto, C.; Piozzi, A.; Donelli, G. Antifouling and antimicrobial biomaterials: an overview. Apmis 2017, 125 (4), 392417.

(16) Kobayashi, S.; Hiroishi, K.; Tokunoh, M.; Saegusa, T. Chelating properties of linear and branched poly (ethylenimines). Macromolecules 1987, 20 (7), 1496-1500.

(17) Didas, S. A.; Choi, S.; Chaikittisilp, W.; Jones, C. W. Amineoxide hybrid materials for $\mathrm{CO} 2$ capture from ambient air. Acc. Chem. Res. 2015, 48 (10), 2680-2687.

(18) Shen, X.; Du, H.; Mullins, R. H.; Kommalapati, R. R. Polyethylenimine applications in carbon dioxide capture and separation: from theoretical study to experimental work. Energy Technology 2017, 5 (6), 822-833.

(19) Lambermont-Thijs, H. M. L.; van der Woerdt, F. S.; Baumgaertel, A.; Bonami, L.; Du Prez, F. E.; Schubert, U. S.; Hoogenboom, R. Linear Poly(ethylene imine)s by Acidic Hydrolysis of Poly(2-oxazoline)s: Kinetic Screening, Thermal Properties, and Temperature-Induced Solubility Transitions. Macromolecules 2010, 43 (2), 927-933.

(20) Tauhardt, L.; Kempe, K.; Knop, K.; Altuntaş, E.; Jäger, M.; Schubert, S.; Fischer, D.; Schubert, U. S. Linear Polyethyleneimine: Optimized Synthesis and Characterization - On the Way to "Pharmagrade" Batches. Macromol. Chem. Phys. 2011, 212 (17), $1918-1924$

(21) Tauhardt, L.; Kempe, K.; Schubert, U. S. Toward the design of LPEI containing block copolymers: Improved synthesis protocol, selective hydrolysis, and detailed characterization. J. Polym. Sci., Part A: Polym. Chem. 2012, 50 (21), 4516-4523.

(22) Monnery, B. D.; Hoogenboom, R. Synthesis and Properties of Polyalkylenimines; 2014; pp 30-61, Chapter 2.

(23) Hoogenboom, R. 50 years of poly(2-oxazoline)s. Eur. Polym. J. 2017, 88, 448-450.

(24) Verbraeken, B.; Monnery, B. D.; Lava, K.; Hoogenboom, R. The chemistry of poly(2-oxazoline)s. Eur. Polym. J. 2017, 88, 451469.

(25) Hoogenboom, R.; Fijten, M. W.; Thijs, H. M.; van Lankvelt, B. M.; Schubert, U. S. Microwave-assisted synthesis and properties of a series of poly (2-alkyl-2-oxazoline) s. Des. Monomers Polym. 2005, 8 (6), 659-671.

(26) Wiesbrock, F.; Hoogenboom, R.; Leenen, M. A.; Meier, M. A.; Schubert, U. S. Investigation of the living cationic ring-opening polymerization of 2-methyl-, 2-ethyl-, 2-nonyl-, and 2-phenyl-2oxazoline in a single-mode microwave reactor. Macromolecules 2005, 38 (12), 5025-5034.

(27) Perevyazko, I.; Gubarev, A. S.; Tauhardt, L.; Dobrodumov, A.; Pavlov, G. M.; Schubert, U. S. Linear poly(ethylene imine)s: true molar masses, solution properties and conformation. Polym. Chem. 2017, 8 (46), 7169-7179.

(28) Weyts, K. F.; Goethals, E. J. New synthesis of linear polyethyleneimine. Polym. Bull. 1988, 19 (1), 13-19.

(29) Rieger, E.; Manhart, A.; Wurm, F. R. Multihydroxy Polyamines by Living Anionic Polymerization of Aziridines. ACS Macro Lett. 2016, 5 (2), 195-198.

(30) Reisman, L.; Mbarushimana, C. P.; Cassidy, S. J.; Rupar, P. A. Living Anionic Copolymerization of 1-(Alkylsulfonyl)aziridines to Form Poly(sulfonylaziridine) and Linear Poly(ethylenimine). ACS Macro Lett. 2016, 5 (10), 1137-1140.

(31) Javorskis, T.; Orentas, E. Chemoselective Deprotection of Sulfonamides Under Acidic Conditions: Scope, Sulfonyl Group Migration, and Synthetic Applications. J. Org. Chem. 2017, 82 (24), 13423-13439.

(32) Mbarushimana, P. C.; Liang, Q.; Allred, J. M.; Rupar, P. A. Polymerizations of Nitrophenylsulfonyl-Activated Aziridines. Macromolecules 2018, 51 (3), 977-983.

(33) Rieger, E.; Alkan, A.; Manhart, A.; Wagner, M.; Wurm, F. R. Sequence-Controlled Polymers via Simultaneous Living Anionic Copolymerization of Competing Monomers. Macromol. Rapid Commun. 2016, 37 (10), 833-839. 
(34) Altuntaş, E.; Knop, K.; Tauhardt, L.; Kempe, K.; Crecelius, A. C.; Jäger, M.; Hager, M. D.; Schubert, U. S. Tandem mass spectrometry of poly (ethylene imine) s by electrospray ionization (ESI) and matrix-assisted laser desorption/ionization (MALDI). J. Mass Spectrom. 2012, 47 (1), 105-114. 